\title{
MEIOS DIGITAIS COMO GARANTIA DO ACESSO AO DIREITO À EDUCAÇÃO
}

\author{
Hayalla Stephanie Lisboa Marques Santa Rosa \\ Jefison de Andrade das Chagas ${ }^{1}$
}

\section{Resumo}

O presente estudo se destina a fazer uma breve análise sobre o direito social à educação, sua influência para o alcance da dignidade da pessoa humana e o seu alcance no formato EAD no Brasil. $O$ artigo trata das metodologias de ensino viabilizadas pelo EAD, qual a sua contribuição na formação desses jovens e crianças e se a fruição dos benefícios desse método de ensino são possível por todas as classes sociais de forma isonômica. A pretensão é analisar como o EAD pode trazer a democratização do ensino no país e qual caminho viabilizará isto. Palavras-chave: Direito a educação, Ensino a distância, Metodologias de Ensino, Democratização, Isonomia de Direitos

\section{DIGITAL MEDIA AS A GUARANTEE OF ACCESS TO THE RIGHT TO EDUCATION}

\begin{abstract}
This study is intended to make a brief analysis of the social right to education, its influence on the achievement of human dignity and its reach in the distance learning format in Brazil. The article deals with the teaching methodologies made possible by EAD, what is their contribution in the formation of these young people and children and if the enjoyment of the benefits of this teaching method are possible for all social classes in an isonomic way. The intention is to analyze how distance education can bring the democratization of education in the country and which path will make this possible.
\end{abstract}

Keywords: Right to education, Distance learning, Teaching methodologies, Democratization, Isonomy of rights

\section{INTRODUÇÃO}

O direito a educação, ainda que recente em nossa legislação, se comparado com outros direitos, detém a importância de um direito fundamental de caráter social, ou direito fundamental de segunda geração, para alguns autores, tamanha a sua importância.

Diretamente relacionado com a dignidade da pessoa humana e a relação desse princípio com os demais direitos fundamentais, a viabilização da educação, em especial a de base, é

\footnotetext{
${ }^{1}$ Mestrandos em Constitucionalização do Direito pelo Programa de Pós-graduação em Direito da Universidade Federal de Sergipe na Linha de Pesquisa 1: Processo de Constitucionalização Dos Direitos e Cidadania: aspectos teóricos e metodológicos.

Endereço eletrônico: hayallaadv@hotmail.com
} 
importante ainda para a formação do ser humano como cidadão e consequentemente como sabedor dos seus direitos e deveres em uma sociedade.

Grande patrono e defensor da educação no Brasil, Paulo Freire prega que a educação não muda o mundo, mas muda as pessoas e as pessoas mudam o mundo. Assim, percebe-se a educação como importante instrumento de mudança e desenvolvimento de uma sociedade.

Entretanto, apesar do caráter essencial do direito à educação, dado pela legislação constitucional, infra e supra constitucional, e ainda por tratados internacionais, o usufruto desse direito ainda não alcançou os patamares pretendidos pelo Brasil para se equiparar aos países de primeiro mundo.

A democratização do ensino no Brasil é uma problemática presente na agenda política desde a inserção da obrigatoriedade do ensino em nossa legislação. Assim como a democratização de outros direitos sociais, é dificultada e as vezes até mesmo inviabilizada pelas barreiras sociais e pelas barreiras físicas existentes no país de dimensões geográficas tão extensas.

Enquanto nos países de primeiro mundo, o alcance a educação e alfabetização chega a quase toda a população de forma isonômica e justa, o Brasil é detentor de índices altos de analfabetismo, especialmente o funcional, e de grande disparidade do acesso aos níveis superiores de ensino. Enquanto em torno de 18,3\% dos jovens negros entre 18 e 24 anos cursam o ensino superior, $36,1 \%$ dos brancos estão em universidades.

Além do recorte racial, também observa-se ainda uma grande disparidade de efetivação da educação, em especial em níveis de pós graduação, entre os brasileiros de escola privada, com situação financeira mais confortável, e os brasileiros de escola pública, que fazem parte da parcela mais pobre da população.

A política de cotas para as universidades públicas, implementada em 2012, que separa 50\% das vagas para os alunos de escola pública, ainda divididos em subgrupos raciais, foi um grande potencializador dessas políticas afirmativas para a promoção do acesso a educação. 
Apesar disso, a democratização do ensino como um todo, em níveis de analfabetismo ou de acesso ao nível superior, ainda perpassa por diversas barreiras para a sua efetivação.

Em paralelo a isto, seguindo os moldes universais de globalização e maior acesso à internet e ao universo virtual, observou-se o crescimento das metodologias de ensino virtual, o Ensino a Distância, em que novas possibilidades de aprendizagem e ensino são viabilizadas.

Durante o último ano e com a eclosão da luta contra o Covid-19, com a necessidade do isolamento social, observamos a necessidade de funcionamento e aplicação do EAD, que já era utilizado por algumas instituições privadas, também pelas públicas, e surgiram questionamentos da efetividade dessa metodologia de ensino.

Questiona-se ainda as possibilidades de aplicação de outras metodologias de ensino, mais antigas, dentro do ensino a distância de forma virtual, e quais benefícios ao aprendizado de crianças, jovens e adultos são possíveis.

Mais, questiona-se a viabilidade da democratização desse formato de ensino no país com tão grande disparidade de acesso à educação tradicional e quais as medidas a serem tomadas para a aplicação dos meios virtuais como instrumento do usufruto do direito social à educação. Esses são os questionamentos que serão abordados e destrinchados nos tópicos a seguir.

\section{DO DIREITO FUNDAMENTAL À EDUCAÇÃO}

A sociedade está em constante mutação, e suas dinâmicas se alteram com facilidade e rapidez. As prioridades sociais e estatais mudam na mesma velocidade e direitos defendidos e priorizados numa era já não são percebidos da mesma forma em outra. Mas seja millenial, geração $\mathrm{z}$ ou $\mathrm{x}$, toda geração passa pela educação até chegar na mudança. É este, indubitavelmente, o maior instrumento de modificação social, em qualquer era.

Russeau, em 1762 - com edição de 1992 - já entendia que nascemos fracos, precisamos de força; nascemos desprovidos de tudo, temos necessidade de assistência; nascemos estúpidos, precisamos de juízo. Tudo o que não temos ao nascer, e de que precisamos adultos, é nos dado pela educação. 
Todas as grandes revoluções industriais contaram com filósofos, engenheiros e grandes estudiosos das mais diversas áreas, para possibilitar e trazer luz à necessidade de mudança. Hoje, alguns séculos depois, tão perto, para alguns, de uma quarta revolução industrial, a de inteligências artificiais, seguimos reafirmando as possibilidades e caminhos que são dados a partir da educação.

Nesse contexto, questiona-se o que é de fato educação. Segundo a Lei de Diretrizes e Bases da Educação Nacional, n 9.394, de 20 de dezembro de 1996, a educação abrange os processos formativos que se desenvolvem na vida familiar, na convivência humana, no trabalho, nas instituições de ensino e pesquisa, nos movimentos sociais e organizações da sociedade civil e nas manifestações culturais.

Já Émile Durkheim, conceituou educação como

ação exercida pelas gerações adultas sobre as gerações que não se encontram preparadas para a vida social; tem por objetivo suscitar e desenvolver, na criança, certo número de estados físico, intelectuais e morais, reclamados pela sociedade política, no seu conjunto, e pelo meio especial a que a criança, particularmente, se destine. (DURKHEIM, 2013, p s/n)

Juridicamente, a educação é tanto uma preocupação quanto uma prioridade em todas as esferas Estatais, supra e infra estatais. Garantido constitucionalmente somente a partir de 1988, esse direito social alcançou diversas outras legislações que a regulem e possibilitem seu acesso a ela, possibilitadas pelo direito constitucional.

Até a Constituição de 1988, o direito à educação era tratado como uma assistência, possível de ser viabilizada pelo Estado, mas não como uma obrigação deste Estado garantir a educação de qualidade e de forma gratuita a todos.

Art. 205. A educação, direito de todos e dever do Estado e da família, será promovida e incentivada com a colaboração da sociedade, visando ao pleno desenvolvimento da pessoa, seu preparo para o exercício da cidadania e sua qualificação para o trabalho. 
Os direitos sociais, como o direito a educação, possibilitam o alcance da dignidade, defendida como princípio básico dos direitos fundamentais. Ou seja, ainda que não tenha força de direito fundamental, o direito à educação é tão essencial quanto se fosse.

A elevação da educação a um direito consubstanciou-se no reconhecimento da sua importância para a promoção da dignidade da pessoa humana, em especial pela sua imprescindibilidade para o consciente exercício da cidadania. Seu reconhecimento não resulta em mera positivação, mas essencialmente em sua exigibilidade por qualquer indivíduo que por ela, pode expandir sem limites a capacidade universal humana de participar, de forma ativa e inteligente, da produção econômica e da gestão política, e de pensar e sentir na dimensão filosófica e artística. (BASILIO, 2009, p 22)

Além da defesa constitucional, o direito à educação é garantido ainda em outras legislações, quais sejam a Lei de Diretrizes e Bases da Educação Nacional (Lei n. 9.394/96), o Estatuto da Criança e do Adolescente (Lei n. 8.069/90), o Plano Nacional de Educação (Lei n. 10.172/2001), entre outros.

A lei de diretrizes e bases da educação nacional, conhecida com carta magna da educação, dispõe e estabelece as direções a serem tomadas por todo o sistema educacional, público ou privado, da educação básica ao nível superior. Disposto em seu corpo legislativo, está que a educação, dever da família e do Estado, inspirada nos princípios de liberdade e nos ideais de solidariedade humana, tem por finalidade o pleno desenvolvimento do educando, seu preparo para o exercício da cidadania e sua qualificação para o trabalho.

No plano internacional, ainda em 1966 a ONU viabilizou o Pacto Internacional dos Direitos Econômicos, Sociais e Culturais, que trazia em seu corpo a defesa ao direito à educação, e a obrigação dos Estados que aderiram ao pacto de promovê-la e universalizá-la. O Brasil aderiu ao pacto oficialmente em 1992, reafirmando a promoção ao direito à educação.

Nesse sentido, o pacto determina que nos Estados em que não se garanta, quando de sua assinatura, a obrigatoriedade ou gratuidade do ensino fundamental (primário), deverá ser elaborado num prazo de dois anos um plano de ação destinado à sua efetiva implementação. (BASILIO, 2009, p 23)

Ainda sobre o Pacto, dispõe Duarte, 2017 
$\mathrm{O}$ aspecto social gera obrigações estatais positivas tendentes a tornar o direito à educação primária disponível e acessível a todos, incluindo crianças de rua, comunidades rurais dispersas, portadores de necessidades especiais etc. Cabe aos Estados-partes a aplicação de investimentos para a organização e manutenção de um sistema público de educação capaz de garantir o acesso de todos a escolas públicas, sempre de acordo com o princípio da não-discriminação. Ressalte-se, ainda, que o Pacto impõe não apenas a responsabilidade de tornar a educação primária gratuita, como também compulsória. No que diz respeito aos objetivos educacionais, o Pacto retoma o espírito da Declaração Universal dos Direitos Humanos, de 1948 (especialmente art. 26, II), reforçando sua imperatividade. (DUARTE, 2017, p 7)

Assim, observa-se o caráter fundamental e universal do acesso à educação para uma sociedade desenvolvida devidamente. É de extrema importância que os níveis de aprendizado, escolaridade e alfabetização sejam sempre analisados, possibilitando reflexões sobre melhoras e evolução naquele nível de ensino.

O acesso à educação foi, e continua sendo, importante preocupação social e governamental, especialmente por se verificar que é possível a inclusão social como resultado do processo educacional. Porém, o acesso formal aos bancos escolares não deve estar limitado aos números de alunos que ingressam o sistema escolar. É preciso, também, assegurar-lhes o direito a uma educação com qualidade, princípio, aliás, sedimentado em sede constitucional (art. 206, inciso VII, da Constituição). (GOTTEMS, 2012, p s/n)

Outrossim, aquém da importância e da dimensão dada a educação em todas as esferas nacional, estrangeira, legislativa, social -, ainda nos deparamos com dados tão desanimadores do acesso à educação e da efetividade do aprendizado nas escolas brasileiras.

Segundo o INAF - Indicador de Analfabetismo Funcional, na pesquisa de 2018, 8\% da população brasileira ainda era completamente analfabeto, e $29 \%$ é de analfabetos funcionais, que são, ainda segundo o relatório do INAF, são pessoas que têm muita dificuldade para fazer uso da leitura e da escrita e das operações matemáticas em situações da vida cotidiana, como reconhecer informações em um cartaz ou folheto ou ainda fazer operações aritméticas simples com valores de grandeza superior às centenas.

Outrossim, quando colocado o referencial raça/cor como parâmetro de observação das taxas de analfabetismo, mais uma vez os dados são chocantes, tendo em vista que entre pretos a $8 \%$ 
da população é completamente analfabeta, enquanto apenas 3\% dos brancos são. Ainda, penas $12 \%$ dos autodeclarados negros chegam ao nível superior, em contraste com os $25 \%$ dos autodeclarados brancos que chegam às universidades.

Utilizando outro parâmetro e uma amostra mais recente, no Censo Escolar 2020, divulgado pelo INEP, em parceria com o Ministério da Educação, restou claro que, entre os jovens de 14 a 29 anos, é quase $20 \%$ a taxa de evasão escolar, ou seja, abandono após concluir apenas algumas etapas da educação básica.

Mais uma vez, dentre esse grupo, quase $70 \%$ são pretos e pardos, e os motivos para o abandono são em grande maioria pela necessidade de trabalhar, e ainda há uma porcentagem de desinteresse no ensino.

O fato é que, diferente dos países de primeiro mundo, o Brasil ainda precisa percorrer um longo caminho até eliminar o analfabetismo e alcançar o mesmo patamar destes países no acesso à educação. Apesar disso, os meios digitais e o ensino remoto apresenta-se como uma nova possibilidade, se devidamente investido e preparado, de possibilitar a plenitude do direito fundamental à educação.

\section{MEIOS DIGITAIS COMO A METODOLOGIA DE ENSINO DO SÉCULO}

Durante o último ano o mundo precisou se readaptar e encontrar formas de seguir com a normalidade, ou nova normalidade, da vida civil em um universo pandêmico e de isolamento social. Os métodos físicos de trabalho, estudo e relações interpessoais já não eram possíveis e tampouco era possível parar. O mundo físico foi transportado para o virtual.

O ensino, assim como outras searas, passou por uma readaptação e reencontro de objetivos para entender como seriam possíveis mantê-los dentro das barreiras da nova normalidade. Dentro do EAD, Ensino A Distância, algumas técnicas e metodologias de ensino já não eram possíveis de serem aplicadas. Outras possibilidades surgiram e novas estratégias foram adotadas para o melhor aproveitamento desse tipo de ensino. 
Recordamos que a educação a distância em regime online partilha atributos com a educação presencial, tais como: as oportunidades para o discurso humano em direto, a colaboração em grupo e o incremento da aprendizagem ativa. Para esta investigadora, a educação online assenta em três princípios: (1) princípio da colaboração; (2) princípio do acesso e (3) princípio da construção sobre o conhecimento. (GASPAR, 2003, p. 66)

Inicialmente, é importante inserir-se no contexto global de maior acesso à internet e às informações a partir dela. No Brasil, atualmente, na Pesquisa Nacional por Amostra de Domicílios Contínua, divulgada pelo IBGE, Instituto Brasileiro de Geografia e Estatísticas, referente ao ano de 2019, observou-se que quase $79 \%$ da população brasileira tem acesso à internet. Quando observado entre os jovens, esse número cresce para quase $98 \%$.

Sendo assim, um novo universo é apresentado a estes jovens, com novas possibilidades de informação, sem necessariamente um amparo para que todas essas novas informações sejam transformadas em aprendizagem.

GASPAR, 2003, p 67, ao citar Damásio, menciona que a transformação da informação em conhecimento é particularmente importante e relevante. Será imperativo conhecer modos de operar com a informação para a transformar em conhecimento. Aqui se situam dois importantes objetivos da educação: “aprender a aprender" e “aprender a conhecer". O conhecimento é um complexo processo que mobiliza a inteligência cognitiva, afetiva, emocional e expressiva.

O ensino a distância, em regime online, centra-se essencialmente no aluno como pessoa e pode implementar metodologias que valorizam aquilo que Matias Alves (1998) designa de "competências mais mobilizadoras": a capacidade de iniciativa, a cooperação, o trabalho em equipa, a comunicação e o saber aprender. Associa o que Hilary Steedman (1998) identifica como quatro domínios de competências a desenvolver em qualquer modalidade de ensino, dentro do sistema de educação formal: resolução de problemas, capacidades de comunicação, conhecimento e compreensão dos mecanismos sociais e capacidade de auto-avaliação e de auto-responsabilização pelo próprio desenvolvimento. (GASPAR, 2003, 67)

Ou seja, diverso do ensino presencial, com o acompanhamento tão próximo do professor em todo o processo, o ensino a distância potencializa a capacidade autodidata dos alunos e a sua 
independência. Fazendo com que o seu aprendizado seja advindo de uma compreensão de todo o meio ao redor, e consequentes reflexão e crítica disso.

Fazendo um link com as perspectivas de ensino, observamos aqui que o ensino online possibilita a aplicação da conhecida perspectiva humanista, com um viés mais moderno, ou ainda uma educação com foco pedagógico construtivista, que seriam a educação com maior foco no aluno e nas possibilidades de facilitação do ensino para esse aluno.

Segundo GIL, 2009, a perspectiva humanista de ensino, inspirada em Locke, Russeau e Froebel, dá mais ênfase à liberdade do aluno. Aqui, a escola constitui a instituição mais tradicional, rígida e burocrática existente, e o enfoque no aluno e na aprendizagem são uma solução para isso, onde as crianças escolheriam seu próprio ritmo de aprendizagem.

Esse tipo de ensino é veementemente defendido por Paulo Freire, que acredita que a educação não deve ser pautada na figura do professor e no ato de ensinar, mas sim no papel do aluno e no ato de aprender. O professor seria apenas um facilitador, para que a educação não se torne apenas deposito de valores e conhecimentos naquele aluno.

\begin{abstract}
A narração de que o educador é o sujeito, conduz os educandos à memorização mecânica do conteúdo narrado. Mais ainda, a narração os transforma em "vasilhas", em recipientes a serem "preenchidos" pelo educador. Quanto mais vá enchendo os recipientes com seus "depósitos", tanto melhor educador será. Quanto mais se deixarem totalmente "encher" tanto melhores educandos serão. (FREIRE, 2002, p 66)
\end{abstract}

Assim, o ensino EAD seria uma viabilização desse ensino, ainda que rígido por seguir as diretrizes e os moldes estabelecidos também para a sala de aula, mas com um maior caráter libertário para o aluno cresça em conhecimento, autonomia e cidadania.

COSTA, 2016, citando C. V. A. Almeida, observa que o papel do professor transmuta-se no EAD, e em linhas gerais ele deve apresentar os seguintes atributos:

a) Pressupor a participação-intervenção dos alunos, sabendo que participar é muito mais que responder "sim" ou "não", é muito mais que escolher uma opção dada; participar é atuar na construção do conhecimento e da comunicação; b) Garantir a bidirecionalidade da emissão e recepção, sabendo que a comunicação e a aprendizagem são 
produzidas pela ação conjunta do professor e dos alunos; c) Disponibilizar múltiplas redes articulatórias, sabendo que não se propõe uma mensagem fechada, ao contrário, se oferece informações em redes de conexões, permitindo ao receptor ampla liberdade de associações, de significações; d) Engendrar a cooperação, sabendo que a comunicação e o conhecimento se constroem entre alunos e professor como cocriação e não no trabalho solitário; e) Suscitar a expressão e a confrontação das subjetividades, sabendo que a fala livre e plural supõe lidar com as diferenças na construção da tolerância e da democracia. (COSTA, 2016, p 58)

Assim, levando-se em conta essa caraterística mais livre dos alunos no EAD, e as possibilidades de metodologias a serem adotadas para melhor otimizar este ensino, GASPAR, 2003, menciona duas: a da resolução de problemas (poderá incluir-se no trabalho em grupo) e a do foco organizador (= advancer organizer).

Abordemos aqui a metodologia de resolução de problemas como ótima adaptação para o EAD.

Essa metodologia, apesar de facilmente aplicada ao ensino digital, foi preconizada por Jhon Dewey, em 1897. GASPAR, 2003, ao mencioná-lo, explica que Dewey traz o “projeto", que coloca o aprendente perante um problema. A resolução do problema pressupõe um trabalho de elaboração seguindo um plano que inclui o estudo das condições e uma antecipação intelectual das consequências. Toda a pesquisa parte, sem dúvida, de uma situação problemática de incerteza e de dúvida.

$\mathrm{Na}$ perspectiva deste teórico, os princípios da continuidade e da interacção, no ensino-aprendizagem, não são separados um do outro. O princípio de que o desenvolvimento da experiência vem através da interacção significa que a educação é essencialmente um processo social. Daí ele afirmar que o processo de aprendizagem deverá passar pela cooperação e não pela "dictação". Logo a preocupação, no ensinar, deverá ser colocada na acentuação em desenvolver a capacidade para "solucionar/resolver problemas".(GASPAR, 2003, p 69)

Essa metodologia de Dewey foi aprimorada ao longo do tempo, desenvolvendo o método de "investigação em grupo", focado na interpessoalidade e intercomunicação. Esse método organiza-se em 6 partes:

$\mathrm{Na}$ fase um cria-se uma situação desordenada (como se se tratasse das peças de um puzzle); na fase dois exploram-se as reações a essa situação; na fase três decidem-se e planificam-se as tarefas; na fase 
quatro desenvolve-se o estudo independente (individual) e em grupo; na fase cinco analisa-se o processo desenvolvido e o progresso conseguido e na fase seis conclui-se com a identificação dos resultados e decisão sobre a "reciclagem" da atividade, se necessário. (GASPAR, 2003, p 70)

Outrossim, fica evidente os motivos que possibilitam a aplicação da resolução de problemas e da investigação em grupo para o ensino a distância, haja vista que faz-se necessária a criação dessa comunidade de forma virtual, a pesquisa e trabalho individual, livre e independente para a colaboração do todo no trabalho da comunidade.

No mais, analisando o panorama geral do ensino a distância, ainda que no brasil a efetiva aplicação dele tenha se dado de forma compulsória, por conta da situação pandêmica, são grandes os benefícios para a manutenção desse método de ensino mesmo no retorno à normalidade. A maior facilitação aprender a aprender, aprender a ser, e aprender a conhecer, viabilizados pelo $\mathrm{EAD}$, são alguns desses benefícios, que geram alunos-cidadãos com senso crítico e maior autonomia na vida pessoal. Entretanto, no que pese os benefícios desse método, questiona-se a possibilidade de aplicação democrática do mesmo, o que analisaremos no tópico a seguir.

\section{DEMOCRATIZAÇÃO DO ENSINO NO EAD}

Como já perpassado, Paulo Freire, 2002, foi grande defensor da Pedagogia de Libertação e consequentemente do que ele chama de ensino problematizador, que objetiva formar cidadãos conscientes dos problemas da sociedade e com senso crítico aguçado, sendo capazes então de não levar para a sala de aula esse sistema opressor que desfavorece os menos privilegiados e favorece aqueles que tem melhor condição econômico-financeira.

Freire acredita que os indivíduos, a partir desta educação, são capazes de trazer essa revolução social que o Brasil precisa, para uma isonomia de direitos como um todo.

Dai, a necessidade que se impõe de superar a situação opressora. Isto implica no reconhecimento crítico, na "razão" desta situação, para que, através de uma ação transformadora que incida sobre ela, se instaure uma outra, que possibilite aquela busca do ser mais. (FREIRE, 2002, p 22) 
Assim, seguindo essa linha de raciocínio progressista e libertária de Paulo Freira, a educação libertária é ainda mais importante para aqueles que precisam dessa mudança social e dos efeitos dela em suas vidas individuais. Os indivíduos, já mencionado nos tópicos acima, que vivem em situação de desprivilegio financeiro e consequentemente social no Brasil, podem se utilizar dessas mudanças para uma progressão de qualidade de vida.

Nesta nova fase da educação a distância, em que as novas tecnologias têm de ser integradas em estratégias educativas, importará, sem dúvida, dar especial atenção às metodologias de ensino que, além de promoverem a aprendizagem linear, permitam a aquisição e desenvolvimento de competências em cidadãos adultos, grupo que constitui, por excelência, a população que opta por esta modalidade de ensino e cada vez mais se envolve no regime online. Este regime exige uma atenção especial à Pedagogia e só com ela a tecnologia pode ter o efeito eficaz no desenvolvimento positivo da própria sociedade. (COSTA, 2016, p 65)

Como mencionado no tópico de acesso ao direito à educação, ao tratar dos dados de evasão do ensino, muitos dos Brasileiros são obrigados a abandonar o aprendizado sem conclui-lo por falta de suporte financeiro que gera a necessidade de trabalhar e consequente falta de tempo hábil para estar nas instituições de ensino.

Desse modo, o ensino a distância se apresenta como um facilitador dessa democratização de ensino, ao trazer o estudo universitário, profissionalizante nas mais diversas áreas, até a tela do computador ou celular, otimizando o tempo de aprendizagem.

Uma das políticas públicas de promoção da democratização do ensino pelo EAD é a Universidade Aberta do Brasil. Um projeto criado pelo ministério da Educação que, de acordo com PEREIRA, 2008, p 51, tem como objetivo estruturar um sistema nacional de educação superior a distância, em caráter experimental, para sistematizar as ações, programas, projetos, atividades pertencentes às políticas públicas.

Esse projeto visa ampliar a oferta do ensino superior gratuito e de qualidade no Brasil, apoiado numa parceria entre consórcios públicos nos três níveis governamentais (federal, estadual e municipal), e conta com a participação das universidades públicas e demais organizações interessadas. 
Os conhecimentos produzidos por algumas universidades públicas, privadas e comunitárias que se aventuravam à oferta de cursos completos ou disciplinas curriculares nessa modalidade, com recursos financeiros e métodos próprios, também foram incorporados às bases teóricas, práticas e metodológicas da UAB. Ressalte-se, porém, que essas iniciativas eram limitadas pela Portaria do MEC n. 2.253/01, que permite a oferta de disciplinas isoladas, na modalidade a distância, desde que não ultrapassasse $20 \%$ da carga horária total dos cursos universitários reconhecidos. (GOMES, 2013, p s/n)

Ainda segundo PEREIRA, 2008, o programa Universidade Aberta do Brasil, em 2007, um ano após ser instituído, disponibilizou 80 mil vagas em cursos de graduação, especialização e aperfeiçoamento. Os cursos são ofertados em 297 municípios por 47 Instituições de Ensino que decidiram colaborar com o projeto.

Outro objetivo do programa é reduzir as desigualdades na oferta de ensino superior e desenvolver um amplo sistema nacional de educação superior a distância. Há polos de apoio para o desenvolvimento de atividades pedagógicas presenciais, em que os alunos entram em contato com tutores e professores e têm acesso a biblioteca e laboratórios de informática, biologia, química e física. Uma das propostas da Universidade Aberta do Brasil (UAB) é formar professores e outros profissionais de educação nas áreas da diversidade. O objetivo é a disseminação e o desenvolvimento de metodologias educacionais de inserção dos temas de áreas como educação de jovens e adultos, educação ambiental, educação patrimonial, educação para os direitos humanos, educação das relações étnico-raciais, de gênero e orientação sexual e temas da atualidade no cotidiano das práticas das redes de ensino pública e privada de educação básica no Brasil. (PORTAL MINISTÉRIO DA EDUCAÇAO)

Hoje o programa UAB conta com 555 polos de apoio, em todos os 26 estados da federação e o distrito federal e possibilita também o aprimoramento de todo o sistema de educação à distância. Ainda, conforme preceitua PEREIRA, 2013, a partir desse programa tem início um processo de democratização do acesso à educação continuada. Isso ocorre por meio da oferta de oportunidade de educação da qualidade para pessoas que estão distantes de centros de formação, impossibilitadas de frequentar os ambientes presenciais e para os tem alguma dificuldade de locomoção.

Entretanto, apesar de não tão recente, o programa e todo o projeto de ensino a distância ainda perpassam algumas problemáticas de aplicação. Os professores, formados para o ensino 
tradicional em sala de aula, nem sempre conseguem facilmente se adaptar ao ensino a distância.

\begin{abstract}
A grande oferta de cursos on-line trouxe um agravamento da situação. Mesmo o docente sentindo-se à vontade com o conteúdo a ser abordado (objeto de estudo e experiência dos seus longos anos de atividade profissional), na maioria das vezes ele desconhece as peculiaridades e especificidades da atuação na docência on-line, principalmente se estamos pensando numa perspectiva que considere a rede como elemento de fortalecimento dos processos de produção de culturas e de conhecimentos e não como mera distribuidora de informações. (COSTA, 2016, p 65)
\end{abstract}

Mais, ainda que grande parte do país esteja, hoje, conectado, há uma parcela da população que ainda não tem fácil acesso aos ambientes de ensino virtuais e/ou ainda são analfabetos virtuais, e ainda não estão passíveis de serem incluídos nessa forma de democratização do ensino.

\title{
5 CONCLUSÃO
}

Aquém de ser um direito social, nem sempre interpretado como direito fundamental pelos autores, a educação se demonstra importante instrumento de mudança e evolução social, além de termômetro da boa gestão de um país.

No Brasil, com índices tão alarmantes de desigualdade social e racial em diversas searas, se entende ainda mais necessário o acesso igualitário à educação de qualidade, possibilitando que jovens e crianças desprivilegiados financeiramente possam alçar novas conquistas de trabalho através dela.

Ainda, na mencionada revolucionária e libertária metodologia de ensino de Paulo Freire, observa-se a necessidade desse ensino formador de senso crítico e cidadania. O ensino feito com o aluno para o aluno e aprendizagem, com enfoque não só no depósito de conhecimento, mas também da resolução de conflitos em sala de aula que possibilite uma futura resolução de conflitos na vida prática. 
E nessa linha, enxerga-se o ensino EAD e os meios virtuais de educação como facilitador do alcance tanto dessa democratização do ensino, como também da maior autonomia do aluno e do aprendizado crítico dele, a partir de interpretações e aprendizados próprios, levados depois para a colaboração do conhecimento em grupo.

Apesar de ainda existir uma longa caminhada até a plena implementação do ensino virtual à distância, seja pela detenção dos meios - internet, computador, tempo - quanto do aperfeiçoamento da metodologia, acredita-se que este é o melhor caminho para a isonomia do acesso ao direito à educação. 


\section{REFERÊNCIAS}

BASILIO, Dione Ribeiro. Direito à educação: um direito essencial ao exercício da cidadania. 2009. Acesso em: <https://www.scielo.br/j/es/a/Sys3c3j8znnWkyMtNhstLtg/?lang=pt> . Em: $15 / 06 / 2021$

BRASIL, Constituição (1988). Constituição da República Federativa do Brasil. Brasília, DF: Centro Gráfico, 1988

BRASIL. Lei de Diretrizes e Bases da Educação Nacional, LDB. São Paulo: Saraiva, 1996. Lei n 9394/1996.

COSTA, Inês Teresa Lyra Gaspar da. Metodologia do ensino a distância. Salvador, BA: UFBA, Faculdade de Ciências Contábeis, Superintendência de Educação a Distância, 2016. 109 p. ISBN 9788582920947 (broch.)

DUARTE, Clarisse Seixas. A educação como um direito fundamental de natureza social. 2007. Acesso em: < https://www.scielo.br/j/es/a/Sys3c3j8znnWkyMtNhstLtg/?lang=pt> . Em $15 / 06 / 2021$

DURKEIM, Émile. Educação e sociologia. Rio de Janeiro: Editora Vozes, 2013.

FREIRE, Paulo. Pedagogia do Oprimido. 38. Ed. São Paulo: Paz e Terra, 2002

GASPAR, Maria Ivone - Duas metodologias de ensino em educação a distância online. "Discursos [Em linha]: perspectivas em educação". ISSN 0872-0738. № 1 (Dez. 2003), p. $65-$ 75

GIL, Antonio Carlos. Metodologia do ensino superior/ Antonio Carlos Gil. - 4 ed. -5 reimpr. - São Paulo: Atlas, 2009.

GOMES, Luiz Fernando. Ead no Brasil: perspectivas e desafios. 2013. Acesso em: < https://www.scielo.br/j/aval/a/8GbQ8WCyB5qGM44ZY4MGj4J/?lang=pt> Em: 19/06/2021 
IGBE - INSTITUTO BRASILEIRO DE GEOGRAFIA E ESTATÍSTICAS. Pesquisa Nacional de Amostra por Domicílios Contínua. 2019. Acesso em: < https://biblioteca.ibge.gov.br/index.php/biblioteca-catalogo?view=detalhes\&id=2101794> Em: 17/06/2021.

INAF - INDICADOR DE ANALFABETISMO SOCIAL. Instituto Paulo Montenegro. Edição 2018. Acesso em: <https://drive.google.com/file/d/lez6jrlrRRUm9JJ3MkwxEUffltjCTEI6/view>. Em 17/06/2021.

INEP - INSTITUTO NACIONAL DE ESTUDOS E PESQUISAS EDUCACIONAIS ANÍSIO TEIXEIRA. Censo Escolar. Edição 2020. Acesso em: $<$ https://download.inep.gov.br/censo escolar/resultados/2020/apresentacao coletiva.pdf $>$. Em $17 / 06 / 2021$

MINISTÉRIO DA EDUCAÇÃO, Portal. Acesso em: <http://portal.mec.gov.br/politica-deeducacao-inclusiva?id=12265>. Em 19/06/2021

PEREIRA, José Matias. POLÍTICAS PÚBLICAS DE EDUCAÇÃO NO BRASIL: A UTILIZAÇÃO DA EAD COMO INSTRUMENTO DE INCLUSÃO SOCIAL. 2008. Journal of Technology Management \& Innovation. Vol. 3

ROUSSEAU, Jean-Jacques. Emílio ou da educação. Rio de Janeiro: Ed. Bertrand Brasi, 1992 